\title{
INTERthesiS
}

\section{RESILIÊNCIA E RECONHECIMENTO EM NEOCOMUNIDADES: O CASO DA COMUNIDADE QUILOMBOLA MORRO DE SÃO JOÃO (TO)}

\begin{abstract}
Alex Pizzio da Silva ${ }^{1}$
Elaine Aparecida Toricelli Cleto $^{2}$

\section{Resumo}

O cenário atual, caracterizado pelas transformações sociais e econômicas impostas pela globalização, tem produzido novos condicionamentos sociais, impactando diretamente as comunidades tradicionais e ampliando a vulnerabilidade. Cada comunidade apresenta maior ou menor capacidade de superação das adversidades. Aquelas que conseguem superá-las e ainda e se fortalecerem são consideradas pelos estudiosos como resilientes. O objetivo deste artigo é apresentar o resultado de uma investigação realizada na comunidade quilombola Morro de São João, no Estado do Tocantins, em que se analisaram sua capacidade de resiliência e os fatores que possibilitam essa condição. A pesquisa desenvolvida possui natureza quanti-qualitativa e foi realizada por meio de um estudo de caso, utilizando como técnicas de coleta de dados a entrevista não estruturada, a observação participante, pesquisa documental, questionário e história de vida, que ocorreram durante as viagens ao campo, ocasião que permitiu também a participação nas cerimônias e nos festejos da comunidade. Os principais conceitos utilizados na análise teórica foram resiliência, neocomunidades, reconhecimento e cultura como recurso. A análise demonstrou que a comunidade possui capacidade de superação das adversidades, e o reconhecimento da identidade cultural constitui um fator de promoção da resiliência.
\end{abstract}

Palavras-chave: Resiliência. Neocomunidades. Quilombola. Reconhecimento. Cultura como recurso.

\section{INTRODUÇÃO}

$\mathrm{Na}$ última década, o Brasil assumiu um lugar de destaque no cenário econômico internacional, resultado de uma política econômica baseada na atração do capital estrangeiro, como fonte de investimentos, e na integração aos mercados internacionais a partir da nova divisão internacional do trabalho. O Brasil chegou a ostentar o sétimo ${ }^{3}$ maior Produto Interno Bruto (PIB) em nível mundial, entretanto ocupa apenas a $75^{a}$ posição no ranking do Índice de Desenvolvimento Humano

\footnotetext{
${ }^{1}$ Doutor em Ciências Sociais pela Universidade do Vale do Rio dos Sinos. Coordenador do Mestrado Profissional em Gestão de Políticas Públicas. Professor no Programa de Pós-Graduação em Desenvolvimento Regional e no Curso de História na Universidade Federal do Tocantins, Palmas, TO, Brasil E-mail: alexpizzio@gmail.com

2 Mestre em Desenvolvimento Regional pelo Programa de Desenvolvimento Regional da Universidade Federal do Tocantins, Palmas, TO, Brasil E-mail: elainecleto@hotmail.com

${ }^{3}$ Em 2015, o Brasil passou a ocupar nona posição.
}

R. Inter. Interdisc. INTERthesis, Florianópolis, v.13, n.3, p.01-22 Set.-Dez. 2016 
(IDH), segundo dados do relatório elaborado pelo Programa para as Nações Unidas (UNDP, 2014). Embora seja um país que vem inovando em termos de políticas sociais de redistribuição e justiça social, apresenta enormes disparidades regionais e intrarregionais não só nos níveis de renda, mas também em indicadores sociais, econômicos e territoriais.

Nessa relação de desenvolvimento desigual, a região amazônica tem se destacado negativamente. Os aspectos relacionados ao seu desenvolvimento há muito tempo ocupam um lugar privilegiado nos embates acadêmicos. Os problemas que dizem respeito à ocupação territorial (BECKER, 2010), aos modelos de desenvolvimento socioeconômico baseados na exploração dos recursos naturais (ARRUDA, 1999; ESCADA; ALVES, 2001), ao extrativismo e ao agronegócio (GREISSIN, 2010), à preservação ambiental, à entrada de capital estrangeiro na região (BUNKER, 2000; COSTA, 2012), à pobreza extrema e ao crescimento sustentável (DINIZ et al., 2007), além dos conflitos sociais locais (SCHMINK; WOOD, 2012), vêm sendo recorrentes em diversos estudos e, não raro, suas ocorrências têm sido tematizadas, considerando-se o impacto dessas questões na vida cotidiana dos povos e comunidades tradicionais ${ }^{4}$.

A questão se torna mais complexa à medida que se constata, cada vez mais, que os processos transnacionais como a globalização econômica, política e cultural têm impactado o país, alterando as dinâmicas sociais e o desenvolvimento da região como um todo. Nesse sentido, pode-se dizer que as transformações ocorridas nas esferas de ação e das relações sociais na realidade contemporânea passam pelo entendimento de que os países desenvolvidos ou em desenvolvimento têm se caracterizado pela passagem do modo de acumulação fordista para o modelo de acumulação flexível (HARVEY, 2003). Todavia, segundo esclarece Lopes (2007), a

\footnotetext{
${ }^{4}$ Adotamos a definição conceitual elaborada por Brandão (2010, p. 37), que entende a comunidade tradicional como um grupo social local que desenvolve: a) dinâmicas temporais de vinculação a um espaço físico que se torna território coletivo pela transformação da natureza, por meio do trabalho de seus fundadores que nele se instalaram; b) saber peculiar, resultante das múltiplas formas de relações integradas à natureza, constituído por conhecimentos, inovações e práticas gerados e transmitidos pela tradição ou pela interface com as dinâmicas da sociedade envolvente; c) uma relativa autonomia para a reprodução de seus membros e da coletividade como uma totalidade social articulada com o "mundo de fora", ainda que quase invisíveis; d) o reconhecimento de si como uma comunidade presente herdeira de nomes, tradições, lugares socializados, direitos de posse e proveito de um território ancestral; e) a atualização pela memória da historicidade de lutas e de resistências no passado e no presente para permanecer no território ancestral; f) a experiência da vida em um território cercado e/ou ameaçado; g) estratégias atuais de acesso a direitos, a mercados de bens menos periféricos e à conservação ambiental.
}

R. Inter. Interdisc. INTERthesis, Florianópolis, v.13, n.3, p.01-22 Set.-Dez. 2016 
configuração dos modos de produção capitalistas atuais não mexeu na estrutura dos processos de exploração do trabalho, mantendo a reprodução profunda das contradições sociais que se assentam sobre os antagonismos estabelecidos na relação propriedade e capital versus força humana e trabalho. No entanto, essa nova configuração escamoteou tal estrutura de forma mais diversificada, uma vez que utilizou, e utiliza, os movimentos mais aparentes da realidade contemporânea para deslocar os eixos de reprodução das relações sociais entre os segmentos, as categorias e grupos de sujeitos com os quais mantém mediações. Em outras palavras, as determinações dos processos de exploração do trabalho, assentadas em uma "nova divisão internacional do trabalho", produzem novos condicionamentos sociais ${ }^{5}$.

Diante de tal cenário, tem chamado atenção a capacidade que alguns grupos ou comunidades apresentam ao superar a adversidade de maneira positiva (HALL; LAMONT, 2013; OJEDA, 2005). Como explicar que alguns grupos ou comunidades, quando submetidos a situações de conflito, risco ou transformação social, demonstrem capacidade de superar a adversidade e, mais ainda, conseguem sair fortalecidos com consequências positivas na projeção de futuro dessas comunidades? Como explicar que algumas comunidades, quando acometidas por situações extremas, reajam quase de imediato, enquanto outras sucumbem? A condição que alguns grupos ou comunidades apresentam de ser capazes de enfrentar os desafios lançados em seu caminho tem sido capturada pela ideia de resiliência.

O objetivo desta pesquisa, portanto, foi refletir acerca do processo de resiliência social e de reconhecimento na comunidade quilombola Morro de São João no Estado do Tocantins ${ }^{6}$.

O desenvolvimento do trabalho de campo demonstrou haver uma relação estreita entre os recursos mobilizados em processos de resiliência e o reconhecimento da identidade cultural. Retomaremos esse aspecto mais adiante.

\footnotetext{
${ }^{5}$ A concepção de novos condicionamentos sociais deriva da compreensão de que as determinações sociais existentes na base das sociedades capitalistas - em sua lógica de produção material e simbólica - configuram novos processos de mediação com a realidade social mais ampla, estrutural, nos períodos de crise pelos quais essas sociedades passaram, e passam atualmente, visando à manutenção de sua hegemonia (LOPES, 2004; 2006).

${ }^{6}$ Doravante, MSJ.
}

R. Inter. Interdisc. INTERthesis, Florianópolis, v.13, n.3, p.01-22 Set.-Dez. 2016 
A comunidade MSJ está localizada no município de Santa Rosa do Tocantins, a cerca de 140 km da capital, Palmas. Em 2006, foi reconhecida como comunidade quilombola pelo governo do estado e pela Fundação Cultural Palmares, e no mesmo ano recebeu sua certificação. Trata-se de uma comunidade que apresenta muitas situações de vulnerabilidade devido à baixa qualidade ou ausência de serviços básicos nas áreas de saúde, educação e saneamento. Suas principais fontes de geração de renda são a agricultura e a criação de gado, complementadas nas temporadas de praia ${ }^{7}$, quando alguns moradores vendem comida e polpa de frutas aos turistas que frequentam o local.

No que tange a seus modos de vida e de produção, os moradores mantêm-se fiéis a formas tradicionais que foram introduzidas por seus antepassados escravizados. Como exemplo, podem-se citar as moradias feitas de adobe ${ }^{8}$, que preservam características das construções do período colonial. Formas tradicionais, entretanto, convivem pari passu com inovações modernas, como energia elétrica, televisão, antena parabólica, celular, computador, entre outras. Outro exemplo advém da reificação da identidade cultural. Conforme se verá adiante, apesar dos impactos que a assimilação das citadas inovações operam no cotidiano da comunidade e no modo de ser e estar dos sujeitos pesquisados, observa-se entre os membros da comunidade um esforço coletivo para se manterem vivas as manifestações culturais típicas herdadas dos antepassados. Preservam-se assim as estruturas sociais responsáveis por produzir e reproduzir a cultura local, por meio de crenças e costumes como os festejos que acontecem anualmente.

É importante destacar que, para Giddens (2009, a produção e reprodução da sociedade deve ser entendida como um complexo estruturado, em que a estrutura corresponde ao

conjunto de regras e recursos implicados, de modo recursivo, na reprodução social; as características institucionalizadas de sistemas sociais têm propriedades estruturais no sentido de que as relações estão estabilizadas através do tempo e do espaço (GIDDENS, 2009, p. XXXV).

\footnotetext{
7 A temporada de praia no Estado do Tocantins corresponde ao mês de julho, período de férias escolares que coincide com o momento de baixa das águas dos rios Tocantins e Araguaia, quando ocorre a formação de áreas de banho conhecidas como praias de água doce.

$8 \mathrm{O}$ adobe é um material vernacular usado na construção civil. É considerado um dos antecedentes históricos do tijolo de barro e seu processo construtivo é uma forma rudimentar de alvenaria. Adobes são tijolos de terra crua, água e palha e algumas vezes outras fibras naturais, moldados em fôrmas por processo artesanal ou semi-industrial.
}

R. Inter. Interdisc. INTERthesis, Florianópolis, v.13, n.3, p.01-22 Set.-Dez. 2016 
Atualmente, a comunidade MSJ é formada por aproximadamente 150 pessoas $^{9}$ e encontra-se diretamente impactada pela crescente exploração dos recursos naturais por parte dos setores hegemônicos da sociedade nacional ligados ao agronegócio. A comunidade tem sido constantemente assediada por produtores rurais para que seus membros transfiram os direitos de propriedade sobre as terras que ocupam, por meio de contratos de compra e venda. Tal situação vem se agravando cada vez mais. Hoje a comunidade se encontra praticamente sitiada, uma vez que todas as terras em seu entorno foram adquiridas por produtores de soja.

As reflexões aqui apresentadas são fruto de um trabalho de campo de tipo etnográfico, realizado durante 12 meses entre os anos de 2014 e 2015. O processo de observação e coleta de dados ocorreu por meio da participação no cotidiano comunitário, nas cerimônias e nos festejos tradicionais que ali ocorrem. Como técnica complementar, foram realizadas dez entrevistas com membros da comunidade. Cabe destacar que, nessas ocasiões, foram observados diversos aspectos que compõem o modo de vida cotidiano da comunidade, bem como elementos culturais e simbólicos utilizados como recursos culturais no sentido descrito por Yúdice (2013), nas suas mais variadas formas de manifestação. A abordagem etnográfica proporcionou aos pesquisadores compreender os desejos, as necessidades e as expectativas sociais manifestadas pelos sujeitos.

\section{A INFLUÊNCIA DOS NOVOS CONDICIONAMENTOS SOCIAIS SOBRE AS COMUNIDADES E O PROCESSO DE RESILIÊNCIA}

Por meio da pesquisa foi possível observar que os processo de globalização e os novos condicionamentos influenciam os sujeitos e, consequentemente, a comunidade como um todo. Nesse sentido, os estudos que visem abordar as dinâmicas que perpassam as sociedades e as comunidades que as compõem necessitam refletir acerca da influência dos processos de globalização e do resultado dessa dinâmica nas questões identitárias e no plano da ação. Como

\footnotetext{
${ }^{9}$ Segundo dados do IBGE (2014), a comunidade é composta por aproximadamente 80 famílias que, juntas, contabilizam cerca de 300 habitantes entre jovens, adultos e crianças. No entanto, com o trabalho de campo verificou-se que esse número é atualmente menor, não sendo possível estimar com precisão a quantidade exata de moradores.
}

R. Inter. Interdisc. INTERthesis, Florianópolis, v.13, n.3, p.01-22 Set.-Dez. 2016 
destaca Octavio lanni (1994), é evidente que, no cenário nacional, aspectos particulares dos indivíduos, grupos, movimentos sociais, cultura etc. continuam vigentes com sua força original. No entanto, simultaneamente, a sociedade nacional se articula de maneira dinâmica e contraditória com as configurações e movimentos da globalização.

Pode-se dizer que essas mudanças tiveram consequências que ultrapassam o âmbito da produção da base material da vida social e, por decorrência, afetaram diretamente os processos de subjetivação da sociedade em geral e da classe trabalhadora em particular. Portanto, é importante perceber como e em que medida essa nova configuração social, produzida a partir dessa reestruturação, implica na formação do Eu (PIZZIO, 2014).

Ainda nessa perspectiva, Giddens (2002) ressalta que na modernidade tardia há situações em que a humanidade, em alguns aspectos, se torna um "nós", enfrentando problemas e oportunidades onde não há "outros". Desse modo, na perspectiva do autor, a modernidade possui ao mesmo tempo elementos de fragmentação e de unificação, ou seja,

A alta modernidade é caracterizada pelo ceticismo generalizado juntamente à razão providencial, em conjunto com o reconhecimento de que a ciência e a tecnologia têm dois gumes, criando novos parâmetros de risco e perigo ao mesmo tempo que oferecem possibilidades benéficas para a humanidade (GIDDENS, 2002, p. 32).

De acordo com Giddens (2002), as disposições globalizantes são inerentes às influências dos elementos que constituem o aspecto dinâmico da modernidade. Nessa perspectiva, a globalização precisa ser entendida como um fenômeno dialético, pois os eventos que ocorrem em um polo de uma relação podem produzir resultados divergentes ou contrários ao serem produzidos no outro - é o que o autor denomina de dialética do local e do global. As transformações que a identidade e a globalização vêm sofrendo são os dois polos dessa dialética, pois as mudanças que têm ocorrido na vida pessoal estão diretamente ligadas ao estabelecimento de conexões sociais de grande amplitude, de maneira que o Eu e a sociedade se encontram inter-relacionados num meio global.

Diante desse panorama de transformações que já se configurava no final do século XX, Castells (2005) destaca que a economia mundial acabou se tornando 
uma economia global ${ }^{10}$, causando uma reestruturação no processo de produção e trazendo, consequentemente, uma nova divisão social e técnica que modificou em grande medida o mundo do trabalho. Entre outras mudanças, esse fenômeno causou maior flexibilização no gerenciamento das relações de trabalho. No que tange às questões sociais, as mudanças também foram drásticas, trazendo a redefinição das relações entre indivíduos e instituições. Os indivíduos tenderam a se reagrupar em torno de identidades primárias, sendo elas religiosas, culturais, étnicas, territoriais. Embora a busca da identidade não seja uma tendência nova, "[...] em um mundo de fluxos globais de riqueza, poder e imagens, a busca da identidade, coletiva ou individual, atribuída ou construída, torna-se a fonte básica de significado social" (CASTELLS, 2005, p. 41). O autor salienta que a busca da identidade é tão poderosa quanto a transformação econômica e tecnológica.

Na sociedade moderna, as identidades precisam ser exploradas e construídas como parte de um processo reflexivo de conectar mudança pessoal e social. Como ressalta Giddens (2002), os sistemas abstratos institucionais estão cada vez mais envolvidos na formação e continuidade da identidade. Para Hall (2008), a identidade não é unificada. Ao contrário, novas identidades estão surgindo, e o indivíduo moderno, que até aqui era visto como sujeito unificado, está se fragmentando cada vez mais. A identidade, segundo o autor, é construída ao longo de discursos, de práticas e posições que podem ser antagônicos, está sujeita a uma historicização radical e constantemente passa por mudança e transformação. De acordo com o autor, a identidade tem a ver com a utilização dos recursos disponíveis na história, na linguagem e na cultura para a produção não somente daquilo que somos, mas principalmente daquilo em que nos tornamos.

Nessa perspectiva, o fato de as identidades modernas terem se deslocado ou se fragmentado vem proporcionando uma descentralização. Desde o final do século XX tem ocorrido uma mudança estrutural que está transformando a sociedade moderna, provocando importantes alterações tanto nas identidades culturais e sociais quanto nas identidades pessoais. Em outras palavras, como sugere Stuart Hall (2006, p. 9), está ocorrendo um processo de "[...] descentração dos indivíduos tanto do seu lugar no mundo social e cultural quanto de si mesmos", o que provoca

10 De acordo com Castells (2005), economia mundial é uma economia em que a acumulação de capital avança por todo o mundo, e economia global é uma economia capaz de funcionar como uma unidade em tempo real e escala global.

R. Inter. Interdisc. INTERthesis, Florianópolis, v.13, n.3, p.01-22 Set.-Dez. 2016 
nos indivíduos uma crise de identidade. Contudo, o autor alerta que o conceito de identidade é muito complexo e pouco desenvolvido, o que dificulta que se ofereçam afirmações conclusivas e julgamentos seguros sobre as teorias contemporâneas.

Diante do que foi exposto, pode-se afirmar que as comunidades não se encontram separadas, isoladas do restante da sociedade; pelo contrário, estão cada vez mais integradas pelo movimento global. A comunidade MSJ é um exemplo dessa integração, pois, ao mesmo tempo que busca manter sua identidade e seu modo de vida protegidos das adversidades, por meio de suas práticas tradicionais, estão inseridas no movimento da globalização e são diretamente impactadas pelas adversidades advindas desse processo. Os impactos são tanto positivos - por meio de benefícios como a tecnologia, a energia elétrica e a geração de renda - como negativos - por meio do desmatamento da área do entorno da comunidade, do avanço de onças em suas terras, a diminuição de água limpa indispensável para a sobrevivência, entre outros.

Segundo Amartya Sen (2000), a articulação entre o desenvolvimento e a cultura se dá de forma tão direta que os vínculos correspondem aos meios e aos fins do desenvolvimento, de maneira que, ao mesmo tempo que a pessoa afeta o processo, é também afetada por ele. Essa concepção pode ser também utilizada no que se refere à globalização e aos novos condicionantes sociais, pois o fenômeno é tão intenso que não é possível mais estar fora de seu movimento. Desse modo, o impacto é inevitável, o que tem provocado novas áreas de imprevisibilidade para as comunidades, levando a um agravamento da vulnerabilidade social. Contudo, o impacto não é o mesmo para todas as comunidades, assim como o enfrentamento e a superação também não o são, pois pode ocorrer que algumas consigam se fortalecer, sendo resilientes, e outras sucumbam diante das adversidades.

No âmbito das Ciências Sociais, há muito vem sendo realizado o debate acerca do fenômeno comunitário e sua articulação com o poder público e os processos de modernização. Mas o que tem mudado para as comunidades com a prática de políticas públicas territoriais e culturais, em voga atualmente, é uma questão de extrema importância, uma vez que o território é concebido como:

o espaço das experiências vividas, onde as relações entre os atores, e destes com a natureza, são relações permeadas pelos sentimentos e pelos simbolismos atribuídos aos lugares. São espaços apropriados por meio de práticas que lhes garantem uma certa identidade social/cultural (BOLIGIAN; ALMEIDA, 2003, p. 241).

R. Inter. Interdisc. INTERthesis, Florianópolis, v.13, n.3, p.01-22 Set.-Dez. 2016 
Giddens (1991), ainda, define o território como um espaço de ação, onde se materializa o subjetivo em sua intencionalidade e o objetivo racional, construindo relações de poder com estrutura social e estrutura cultural.

Tendo esse conjunto de questões como pano de fundo, Lifschitz destaca que essa nova conjuntura tem implicado transformações nas estruturas de produção e reprodução comunitárias, uma vez que "[...] comunidades tradicionais vêm sendo um âmbito privilegiado de políticas públicas e de instituições e agências privadas (agências culturais, ONGs, turismo cultural, dentre outras), e que estas imprimiram mudanças na dinâmica comunitária" (LIFSCHITZ, 2011, p. 13).

A partir das últimas décadas do século $X X$, a criação de políticas públicas voltadas às comunidades tradicionais tornou-se assunto corrente no cenário político, havendo cada vez mais o incentivo a essa prática visando a reconstrução de patrimônios culturais pelas comunidades indígenas e afrodescendentes. No Brasil, o processo de reconstrução da identidade tradicional tem se estendido por todo o país. Lifschitz (2011, p. 30) conceitua esse fenômeno como neocomunidades,

[...] em que agentes modernos desenvolvem projetos voltados para a reconstrução de saberes e práticas tradicionais, que acontecem no próprio espaço da comunidade. [...] nas neocomunidades a identidade e a diferença se inscrevem no mesmo espaço de interação constituindo uma modalidade de contato intercultural.

O conceito descrito por Lifschitz refere-se a territórios nos quais são atualizadas questões que dizem respeito ao universo tradicional, como ancestralidade, parentesco, cultura material e proximidade face a face, mas que ocorrem em contextos relacionais, os quais reconfiguram a relação entre os membros da comunidade e os agentes externos. Contudo, o conceito demonstra que os agentes modernos, embora se interessem também pela cultura material, estão mais interessados no que se produz na própria comunidade, isto é, o território, os saberes e as práticas.

De acordo com o autor, o conceito se refere a três pontos importantes: a ativação de tradições do passado em contextos modernos; a recriação das tradições como estratégia política de legitimação e controle; a possibilidade de múltiplas trajetórias na construção de uma mesma tradição. Os agentes modernos buscam resgatar a aura da comunidade ou sacralizar as práticas que foram se diluindo com o tempo por meio do uso de técnicas e dispositivos modernos, como a internet, a cenografia, vídeos, laudos antropológicos, entre outros, para reproduzir suas tradições. Como diz o autor, o fenômeno da neocomunidade não é uma forma de a R. Inter. Interdisc. INTERthesis, Florianópolis, v.13, n.3, p.01-22 Set.-Dez. 2016 
tradição resistir à modernidade, mas sim uma forma de realizar a tradição por meio da modernidade.

Na América Latina, o que ocorreu foi o incentivo à recriação das identidades tradicionais comunitárias e o reconhecimento dos direitos territoriais e identitários. Tal incentivo ocorreu por meio de políticas culturais fomentadas desde os anos 1960 pela Unesco em toda a América Latina. No Brasil, essas questões ganharam maior destaque com a Constituição de 1988. De acordo com Lifschitz (2011), as comunidades latinas vivenciam um processo de reconstrução e resgate de suas tradições em meio a um contexto caracterizado por constantes mudanças e inovações do mundo moderno e extremamente globalizado. Embora inseridas nessa lógica, a inserção e a relação com o fenômeno não são padrão nem uniformes, pois muitas comunidades conseguem manter seu modo de vida de acordo com suas características tradicionais, enfrentando de maneira resiliente as adversidades provocadas pelo fenômeno.

Segundo Grotberg (2005), o papel da resiliência não é apenas fazer com que o indivíduo supere as adversidades, mas sim que tenha capacidade de enfrentar, vencer e se fortalecer diante das situações adversas e, com isso, possa se transformar. É importar ressaltar que cada cultura possui formas próprias de inculcar nos filhos elementos que promovam a resiliência e a manutenção de sua identidade. Na comunidade MSJ, observou-se que as famílias fazem questão de inserir os filhos desde pequenos na organização, preparação e atuação nos festejos, que são um forte instrumento de manutenção da identidade e também uma forma de reconhecimento da condição de comunidade tradicional. Outro aspecto a destacar é a preocupação dos professores e pais em contar aos filhos a história da comunidade e ensiná-los sobre a importância de manter sua identidade e seus saberes tradicionais, como pode ser observado no relato abaixo:

$\mathrm{Na}$ escola da comunidade tem o dia da contação de histórias e a professora sempre conta para as crianças as histórias sobre os nossos antepassados. Fazem isso para que as crianças aprendam desde cedo que nós somos filhos de preto e a gente tem que ter orgulho disso. (Orlando, 53 anos, lavrador e funcionário público).

Como cada cultura possui particularidades para lidar com a resiliência, é importante não apenas verificar esse processo partindo do enfoque nas reações do indivíduo, e sim perceber como isso ocorre no âmbito coletivo. O que se percebe é que a maioria dos estudos sobre resiliência relaciona o conceito com o indivíduo; todavia, neste trabalho o foco é o processo de resiliência comunitária.

R. Inter. Interdisc. INTERthesis, Florianópolis, v.13, n.3, p.01-22 Set.-Dez. 2016 
De acordo com Ojeda (2005), por resiliência comunitária entende-se a capacidade que grupos ou comunidades têm de se apropriar de recursos culturais e institucionais que existem em seus ambientes com o intuito de enfrentar os desafios gerados pelos novos condicionamentos sociais. $\mathrm{O}$ autor ressalta que a resiliência é hoje uma importante ferramenta no combate à pobreza e à desigualdade. Trata-se de um paradigma, que situa o campo de estudo da resiliência no âmbito coletivo. 0 problema gerado pelos desastres e pelas catástrofes pode significar, segundo Ojeda (2005), o desafio para mobilizar a capacidade de os indivíduos serem solidários, auxiliando no processo de renovação e modernização de toda a estrutura física e social na comunidade. Quando a população se une diante de um problema, e prontamente se organiza para resolvê-lo e melhorar a condição de todo o grupo, isso reflete diretamente na melhoria da saúde física e mental de cada membro, proporcionando-lhes um sentimento de pertencimento ao lugar.

Ojeda (2005) destaca quatro características sociais que considera os pilares mais significativos de resiliência comunitária: autoestima coletiva, identidade cultural, humor social e honestidade estatal. O primeiro se refere ao sentimento de orgulho do cidadão em relação ao lugar em que vive, orgulho de pertencer a esse lugar. Segundo o autor, as comunidades que possuem uma elevada autoestima coletiva possuem maior capacidade de superar as adversidades. A identidade cultural se refere à existência de uma identidade dos cidadãos diante de sua cultura, o que thes proporciona um sentido de permanência no lugar, possibilitando ter força para enfrentar os problemas e defender sua comunidade. Assim, conforme destaca Ojeda, aqueles que respeitam e exaltam sua cultura tradicional têm maior capacidade de se recompor e renascer após a adversidade. Esse fator foi observado na comunidade MSJ, em que os moradores falam de sua tradição com entusiasmo e sentem orgulho de pertencer à comunidade, sentem-se parte de uma mesma família. Lutam para manter sua cultura e sua identidade ativas por meio dos festejos e do reconhecimento da condição de comunidade quilombola. Os relatos a seguir demonstram esse orgulho:

Eu não saio daqui por nada, adoro viver aqui, aqui só tem família, é um pelo outro, até tem umas briguinhas de vez em quando, mas ninguém fica de mal com o outro. Somos uma comunidade. (Marizete, 52 anos, dona de casa e lavradora).

Sou quilombola sim e tenho orgulho de ser. A gente lutou tanto para ser reconhecido e graças a Deus nós conseguimos... Não saio daqui de jeito nenhum. (João, 78 anos, lavrador e ex vereador).

R. Inter. Interdisc. INTERthesis, Florianópolis, v.13, n.3, p.01-22 Set.-Dez. 2016 
Outro pilar importante é a capacidade de alguns grupos encontrarem humor em situações trágicas, obtendo assim um efeito tranquilizador e prazeroso a todos do grupo, o que demonstra que "[...] o humor é uma estratégia de ajuste que ajuda a aceitação madura da desgraça comum e facilita certo distanciamento do problema, favorecendo a tomada de decisões para resolvê-lo" (OJEDA, 2005, p. 51). Quando se utiliza o humor diante de uma adversidade, é possível direcionar o pensamento para encontrar respostas originais, soluções inovadoras. Na comunidade estudada, observou-se que há vários problemas que os deixam muito apreensivos, como, por exemplo, a demarcação que ainda não ocorreu, a água que não é de qualidade e a falta de serviços essenciais efetivos, mas a comunidade não demonstrou desânimo; ao contrário, revelou-se um povo muito alegre, festeiro e forte, que enfrenta as lutas de cabeça erguida e com humor. Isso não significa que na comunidade não existam conflitos e desentendimentos. Alguns moradores relataram que, quando esses ocorrem, tentam logo resolver para não criar situações desagradáveis entre os moradores, já que o contato entre eles é constante. Os relatos a seguir demonstram essa maneira de lidar com os problemas:

Ah, problema todo mundo tem. A gente não pode é desistir, tem que lutar sempre, senão a gente desanima e cai de vez. (Marizete, 52 anos, dona de casa e lavradora).

Graças a Deus não tenho problema, mas quando tenho enfrento, não fico nos cantos lamentando e chorando. A gente tem que rir porque daí o problema vai embora. E tem outra coisa, aqui todo mundo ajuda quando o outro precisa então nós vivemos unidos, somos todos uma só família. (Marcos, 84 anos, aposentado).

O último pilar tratado por Ojeda é o da honestidade coletiva ou estatal, que constitui uma consciência geral, que prima pela honestidade nas ações políticas e administrativas, condenando a desonestidade dos funcionários e valorizando o exercício honesto da função pública. Para que a população tenha a capacidade de ser solidária diante de um problema que afeta a todos, é preciso confiar em quem administra os recursos necessários à realização da reconstrução da sociedade. $\mathrm{Na}$ MSJ, esse elemento pode ser percebido com muita clareza, porque há uma associação e, ainda, vários moradores são funcionários em órgãos públicos localizados na própria comunidade. Conforme afirma um desses funcionários, eles trabalham para a prefeitura, mas também para a comunidade, portanto precisam cuidar com responsabilidade daquilo que é do interesse de todos.

Eu trabalho como vigilante, sou concursado já tem uns dois anos. Se eu quisesse ser desonesto seria porque trabalho a noite e ninguém me vê,

R. Inter. Interdisc. INTERthesis, Florianópolis, v.13, n.3, p.01-22 Set.-Dez. 2016 
porque estão todos dormindo. Então eu poderia vir para minha casa dormir a noite toda e ir para lá de manhã. Não tem ninguém me fiscalizando. Mas eu não faço isso, sabe por quê? Porque eu trabalho para a prefeitura sim, mais também trabalho para comunidade, sou pago para vigiar então tenho que vigiar. (Orlando, 53 anos, lavrador e funcionário público).

No decorrer da pesquisa, observou-se que existe uma relação entre o reconhecimento, a identidade social e a capacidade de resiliência da comunidade MSJ, pois notou-se uma maior capacidade de enfrentar e superar as adversidades quando os sujeitos se sentiam reconhecidos em suas capacidades e qualidades.

Nessa perspectiva, o que se observou é que o reconhecimento da identidade comunitária transmuta-se em um fator promotor de resiliência. $O$ reconhecimento recíproco, que ocorre entre os indivíduos durante a interação social, é fundamental na construção da identidade comunitária, elemento que auxilia nessa superação das adversidades. Isso pode ocorrer porque o espaço em que se dá a interação entre os indivíduos e o desenvolvimento de suas atividades é o mesmo espaço em que estes se redefinem a partir de tal contexto. Como ressalta Pizzio (2014), são nesses espaços de experiência que se descortinam os horizontes de expectativas que são abertas à ação, tanto na organização econômica como na esfera política, lugar de onde pode emergir o sujeito coletivo. Esses contextos locais e nacionais são responsáveis pela definição dos indivíduos e dos grupos como importantes membros da comunidade, conferindo reconhecimento e transformando-os em uma fonte de resistência coletiva.

Partindo do pressuposto de que não há um sujeito universal, pelo contrário, há uma multiplicidade de identidades sociais e culturais constituindo as sociedades contemporâneas, Taylor (2000) defende ser preciso aplicar, com justiça, regras conforme as especificidades de cada meio social. De acordo com Pizzio (2014), para Taylor a necessidade de reconhecimento se dá de maneira urgente nas sociedades contemporâneas devido à relação que há entre reconhecimento e identidade, no qual a identidade designa algo como a compreensão de quem a pessoa é e de suas características definidoras e fundamentais da condição de seres humanos.

$\mathrm{Na}$ perspectiva taylorista, a identidade é moldada em parte pelo reconhecimento ou pela ausência deste, de maneira que uma pessoa ou grupo pode sofrer severas consequências psicológicas e sociais se a sociedade a que pertence Ihe devolver um quadro redutor de si mesmo, desmerecedor ou mesmo desprezível, ou seja, não o reconheça em suas qualidades e utilidades. Isso porque, quando o 
reconhecimento é verdadeiro, tem a capacidade de moldar os indivíduos, enquanto que, quando não existe ou é distorcido, tem o efeito contrário, representando uma forma de agressão, podendo reduzir a pessoa a uma maneira de ser distorcida, restringindo a sua real potencialidade, levando a um falso e reduzido modo de ser (SILVA, 2006; ANDRADE, 2013; PIZZIO, 2014). Assim, o reconhecimento é fundamental para a construção da identidade. Praticá-lo não é apenas um ato de gentileza de um indivíduo para com o outro, mas sim uma necessidade humana vital, pois as deformações que possam existir na identidade estão diretamente relacionadas a ele (SILVA, 2006; ANDRADE, 2013; PIZZIO, 2014).

Segundo Pizzio (2014), Taylor chama atenção para uma questão importante, a de que para compreender a relação entre identidade e reconhecimento é necessário considerar uma característica fundamental da condição humana: a linguagem de caráter dialógico. Seguindo George Mead, "[...] definimos nossa identidade sempre em diálogo com as coisas que os outros significativos desejam ver em nós e por vezes em luta contra essas coisas" (PIZZIO, 2014, s/p). Quando o indivíduo é capaz de compreender a si mesmo e definir sua identidade por meio da interação com outras pessoas, adquirindo a linguagem e outros modos de expressão, é que ele se torna um agente pleno (PIZZIO, 2014; SILVA, 2006). A identidade, então, não é aquilo que o indivíduo constrói por si mesmo, mas o faz de maneira dialógica.

Nessa mesma linha, Honneth (2003) destaca que os indivíduos conseguirão ter plena realização de suas capacidades e uma autorrelação positiva marcada pela integridade, por meio do reconhecimento intersubjetivo, ou seja, se forem reconhecidos pelo seu parceiro de interação (PIZZIO, 2014). Diante disso, em se tratando de comunidades, o sujeito que é reconhecido pelo outro, pelas suas capacidades e atuações dentro do grupo, tem mais possibilidade de ter um crescimento ou desenvolvimento de si mesmo de forma mais positiva, favorecendo também o fortalecimento do grupo para enfrentar as adversidades e ser resiliente. $\mathrm{Na}$ comunidade MSJ, essa característica pode ser encontrada com mais ênfase nos festejos, nas danças, nos cânticos e no modo próprio de lidar com essas tradições, fato que molda a identidade do grupo desde os anciãos até as crianças. Segundo relatos, as festas são planejadas e organizadas em detalhes pelos moradores durante o ano todo. O envolvimento e a interação entre o grupo os fortalecem no

R. Inter. Interdisc. INTERthesis, Florianópolis, v.13, n.3, p.01-22 Set.-Dez. 2016 
sentido de vencer as dificuldades e alcançar o propósito de manter a identidade e a tradição viva.

Na comunidade MSJ, mesmo mantendo seus hábitos e costumes tradicionais o mais próximo possível da maneira como eram feitos por seus antepassados, são influenciados cotidianamente pelos elementos transformadores da globalização. Percebe-se, a todo o momento, a mescla do moderno com o tradicional nos usos e costumes da comunidade. Exemplo disso está nas casas, que são parte de adobe e parte de alvenaria; está também nos eletrodomésticos utilizados nas casas como, por exemplo, o uso do fogão a lenha e do freezer; o caminhar descalço dos mais velhos, contrastado pelo uso do salto ou o uso da chapinha nos cabelos pelas mulheres mais jovens.

Nas relações sociais ocorrem conflitos entre os envolvidos na interação que possibilitam que indivíduo e a sociedade se desenvolvam moralmente ( $\mathrm{PIZZIO}$, 2014). Nessa perspectiva, a autorrealização do sujeito vai depender da relação de reconhecimento que ocorre no processo de interação. Isso porque em uma relação de reconhecimento recíproco, "[...] todo sujeito pode saber-se confirmado como uma pessoa que se distingue de todas as outras por propriedades ou capacidades particulares" (HONNETH, 2003, p. 149).

Diante do que foi apresentado sobre a resiliência e o reconhecimento, percebe-se que é possível relacionar os pilares da resiliência comunitária descrita por Ojeda (2005) com as três formas de reconhecimento descritas por Honneth (2003) no que tange à superação da adversidade. A primeira relação que se pode estabelecer é entre o reconhecimento primário e a característica de humor social da resiliência. Se as relações de amor e amizade estiverem sendo consolidadas dentro da comunidade, isso poderá levar a um reconhecimento recíproco das capacidades e qualidades dos moradores, favorecendo assim a redução de conflitos e a solução dos problemas, estimulando assim a superação da adversidade. A segunda relação é entre o reconhecimento jurídico e a honestidade coletiva presente na resiliência comunitária. A capacidade de ser honesto em ações públicas, ou seja, que dizem respeito ao coletivo, traz ao grupo a possibilidade de se ter confiança de que os direitos e deveres serão cumpridos. Isso promoverá o autorrespeito nos indivíduos, e consequentemente na ordem coletiva, levando à união em prol da superação da adversidade. A terceira e última relação possível se refere ao reconhecimento pautado na comunidade de valor ou solidariedade e as características de autoestima

R. Inter. Interdisc. INTERthesis, Florianópolis, v.13, n.3, p.01-22 Set.-Dez. 2016 
coletiva e identidade cultural. Quando, na existência um problema, a população se une em solidariedade ao grupo, em prol de se organizar para solucioná-lo, isso melhora a situação de todos, trazendo-lhes orgulho de pertencer àquela comunidade e elevando a estima coletiva que favorece a capacidade de superação. Da mesma forma, quando as pessoas respeitam e exaltam sua identidade cultural, isso também Ihes proporciona a vontade de se manterem na comunidade, e força para que enfrentem os problemas e defendam o grupo, possibilitando maior capacidade de superação. Diante dessas relações, é possível concluir que o reconhecimento social da identidade cultural é um fator de resiliência.

$\mathrm{Na}$ comunidade MSJ, observou-se que o reconhecimento entre os moradores é forte. Muitos enfatizaram durante as entrevistas que um procura ajudar o outro a superar suas dificuldades, pois como vivem em comunidade, formando uma grande família, se um deles sofrer, o sofrimento será sentido por todos e impedirá que o grupo se mantenha unido e forte. Há na comunidade o respeito e a preocupação em preservar a interação de maneira harmoniosa e reconhecer reciprocamente o papel e a utilidade de cada um dentro do grupo, nos festejos e nas decisões que precisam ser tomadas em prol da comunidade, com a justificativa de que esse comportamento ajuda a preservar a comunhão e a característica quilombola, ou seja, a identidade cultural.

Constatou-se que entre os membros da comunidade há um sentimento de que terem sido reconhecidos como uma comunidade tradicional fez com que fossem enxergados pelo poder público e pelas instituições sociais e políticas. Como enfatizaram, isso é um fato que possibilita também que os festejos, antes de interesse restrito dos moradores, hoje já atraia vários públicos externos, como pesquisadores, políticos e pessoas influentes da sociedade, que de certa forma os ajudam a superar as adversidades. Nesse sentido, pode-se afirmar que a utilização da cultura por essa comunidade é feita nos moldes do que Yúdice (2013) afirma ser um uso conveniente da cultura.

Outro ponto constatado foi a capacidade de ser resiliente diante das adversidades, pois essa é uma comunidade que, durante os seus 200 anos de existência, enfrentou situações de vulnerabilidade social que foram agravadas com o fenômeno da globalização, o qual produziu novos condicionantes sociais. O fator de reconhecimento da identidade cultural, que leva a um sentimento de pertencimento

R. Inter. Interdisc. INTERthesis, Florianópolis, v.13, n.3, p.01-22 Set.-Dez. 2016 
encontrado entre os moradores, foi considerado um fator de promoção dessa resiliência.

\section{CONSIDERAÇÕES FINAIS}

A relação entre reconhecimento e resiliência constitui um importante mecanismo que auxilia os indivíduos no processo de superação de problemas e construção de identidades, pois a resiliência não é somente a capacidade que os indivíduos possuem de se adaptar e superar as situações adversas, mas também de se desenvolver com essas situações (PIZZIO, 2014). Desse modo, o que vai favorecer que o indivíduo se torne ou não resiliente é a capacidade de construção de si mesmo na interação que estabelece com os que estão a sua volta. A construção social da identidade, enquanto processo contínuo, se exprime no plano coletivo como um fator manipulado, uma vez que os sujeitos dispõem de uma margem de autonomia na definição de si. Nessa perspectiva, pode-se dizer que a produção de um Self resiliente depende da capacidade de gerir e controlar informações dentro de um processo amplo de reflexividade social.

R. Inter. Interdisc. INTERthesis, Florianópolis, v.13, n.3, p.01-22 Set.-Dez. 2016 


\title{
RESILIENCE AND RECOGNITION IN NEOCOMUNIDADES: QUILOMBOLA MORRO DE SÃO JOÃO (TO) COMMUNITY CASE
}

\begin{abstract}
The current situation characterized by social and economic changes imposed by globalization has produced new social conditioning, directly impacting the traditional communities and increasing the vulnerability. Each community has a greater or lesser ability to overcome adversity. Those communities who manage to overcome adversities and even strengthen themselves are considered by scholars as resilient. The aim of this article is to present the result of an investigation in the community quilombo Morro de São João, in the State of Tocantins, in which we analyzed the resilience and the factors that enable this condition. The research developed has quantitative and qualitative nature and was carried out through a case study, using as data collection techniques unstructured interviews, participant observation, document research, questionnaire and life history, which occurred during field trip occasions also allowed to participate in the community ceremonies and festivities. The main concepts used in the theoretical analysis were resilience, neocomunidades, recognition and culture as a resource. The analysis showed that the community has overcome the adversity capacity, and the recognition of the cultural identity is a factor for promoting resilience.
\end{abstract}

Keywords: Resilience. Neocomunidades. Quilombo. Recognition. Culture as a Resource.

\section{RESILIENCIA Y RECONOCIMIENTO EN NEOCOMUNIDADES: EL CASO DE LA COMUNIDAD QUILOMBOLA ${ }^{11}$ MORRO DE SÃO JOÃO (TO)}

\section{Resumen}

La situación actual, caracterizada por cambios sociales y económicos impuestos por la globalización, ha producido nuevos condicionamientos sociales, afectando directamente a las comunidades tradicionales y el aumento de la vulnerabilidad. Cada comunidad tiene una mayor o menor capacidad de superar las adversidades. Las que logran superarlas, e incluso fortalecerse, son considerados por los estudiosos como resilientes. El objetivo de este artículo es presentar los resultados de una investigación en la comunidad quilombola Morro de São João, en el Estado de Tocantins-Brasil, que analiza su capacidad de resiliencia y los factores que permiten esta condición. La investigación desarrollada es de tipo cuantitativo y cualitativo, y se llevó a cabo a través de un estudio de caso, utilizando como técnicas de recolección de datos la entrevista no estructurada, la observación participante, la investigación de documentos, cuestionario y la historia de vida, que se produjeron durante los viajes a campo, ocasión que también permitió participar en las ceremonias y festividades de la comunidad. Los principales conceptos utilizados en el análisis teórico fueron resiliencia, neocomunidades, reconocimiento y cultura como un recurso. El análisis mostró que la comunidad posee capacidad de superación de adversidades, y el reconocimiento de la identidad cultural es un factor de promoción de la resiliencia.

Palabras clave: Capacidad de Recuperación. Neocomunidades. Quilombo. Reconocimiento. Cultura como Recurso.

11 Preferimos mantener el adjetivo en portugués, porque su traducción al español distocería la idea. Deriva del sustantivo quilombo, que en Brasil describe un tipo de escondrijo en lugares muy retirados y de dificil acceso, en el cual se refugiaban los esclavos negros que se escapabana de las haciendas de terratenientes.

R. Inter. Interdisc. INTERthesis, Florianópolis, v.13, n.3, p.01-22 Set.-Dez. 2016 


\section{REFERÊNCIAS}

ANDRADE, Al. A. A política de reconhecimento em Charles Taylor. 2013. 209 f. Dissertação (Mestrado em Filosofia) - Departamento de Filosofia, Faculdade Jesuíta de Filosofia e Teologia - FAJE, Belo Horizonte, 2013. Disponível em: <http://www.faculdadejesuita.edu.br/documentos/280813-3G2QiLB92fKF9.pdf >. Acesso em: 18 abr. 2015.

ARRUDA, R. Populações tradicionais e a proteção dos recursos naturais em Unidades de Conservação. Ambiente \& Sociedade, ano II, n. 5, $2^{\circ}$ semestre, 1999.

BECKER, B. K. Novas territorialidades na Amazônia: desafio às políticas públicas. Bol. Mus. Para. Emílio Goeldi. Ciênc. hum., Belém, v. 5, n. 1, p. 17-23, jan./abr. 2010.

BOLIGIAN, L.; ALMEIDA, R. D. de. A transposição didática do conceito de território no ensino de geografia. In: GERARDI, L. H. de O. (Org.). Ambientes: estudos de geografia. Rio Claro: Unesp; Ageteo, 2003. p. 235-248.

BUNKER, S. Joint ventures em ambientes frágeis: o caso do alumínio na Amazônia. Novos Cadernos do NAEA, v. 3, n. 1, p. 5-45, jun. 2000.

BRANDÃO, C. R. A comunidade tradicional. In: Cerrado, Gerais, Sertão: comunidades tradicionais dos sertões roseanos. Relatório de Pesquisa. Montes Claros, 2010.

CASTELLS, M. A sociedade em rede. 8. ed. Tradução Roneide V. Majer. São Paulo: Paz e Terra, 2005. (A era da Informação: economia, sociedade e cultura. v. 1).

COSTA, F. A. Capital estrangeiro e agricultura na Amazônia: a experiência da Ford Motor Company (1922-1945). Dissertação (Mestrado) - PPG em Ciências Sociais em Desenvolvimento, Agricultura e Sociedade, Universidade Federal Rural do Rio de Janeiro, Rio de Janeiro, 2012.

DINIZ, M. B. et al. A Amazônia (legal) brasileira: evidências de uma condição de armadilha da pobreza? 2007. Disponível em:

<http://www.anpec.org.br/encontro2007/artigos/A07A090.pdf >. Acesso em: 10 out. 2013. 
ESCADA, M. I. S.; ALVES, D. S. Mudanças de uso e cobertura do solo na

Amazônia: impactos socioambientais na ocupação de regiões de fronteira agrícola. Relatório Técnico. Brasília: CT Brasil/Inpe, dez. 2001.

GIDDENS, A. As consequências da modernidade. São Paulo: Editora UNESP, 1991.

Modernidade e identidade. Tradução Plinio Dentzien. Rio de Janeiro: Zahar, 2002.

A constituição da sociedade. 3. ed. São Paulo: Martins Fontes, 2009.

GREISSING, A. A região do jari, do extrativismo ao agronegócio: as contradições do desenvolvimento econômico na Amazônia Florestal no exemplo do projeto Jari. REU, Sorocaba, SP, v. 36, n. 3, p. 43-75, dez. 2010.

GROTBERG, E. H. Introdução: Novas tendências em resiliência. In: MELILLO, A.; OJEDA, E. N. S. (Org.). Resiliência: descobrindo as próprias fortalezas. Tradução Valério Campos. Porto Alegre: Artmed, 2005. p.15-22.

HALL, P. A.; LAMONT, M. Social Resilience in the Neoliberal Era. New York: Cambridge, 2013.

HALL, S. A identidade cultural na pós-modernidade. 11. ed. Tradução Tomaz T. da Silva e Guacira L. Louro. Rio de Janeiro: DP\&A, 2006.

Quem precisa de identidade?. In: SILVA, T. T. da (Org.). Identidade e diferença: a perspectiva dos estudos culturais. 8. ed. Petrópolis: Vozes, 2008. p. 103-133.

HARVEY, D. A condição pós moderna: uma pesquisa sobre as origens da mudança cultural. 12ª ed. São Paulo: Edições Loyola, 2003.

HONNETH, A. Luta por reconhecimento: a gramática moral dos conflitos sociais. Tradução Luiz Repa. São Paulo: Ed. 34, 2003.

IANNI, O. Globalização: novo paradigma das Ciências Sociais. Estudos Avançados, São Paulo, v. 8, n. 21, p. 147-163, maio/ago. 1994. Disponível em: <http://www.scielo.br/scielo.php?script=sci arttext\&pid=S010340141994000200009>. Acesso em: 27 jul. 2014.

R. Inter. Interdisc. INTERthesis, Florianópolis, v.13, n.3, p.01-22 Set.-Dez. 2016 
IBGE - INSTITUTO BRASILEIRO DE GEOGRAFIA E ESTATÍSTICA. Cidades. Rio de Janeiro, 2014. Disponível em: <

http://cidades.ibge.gov.br/xtras/uf.php?lang=\&coduf=17\&search=tocantins >.

Acesso em: 21 jan. 2014.

LIFSCHITZ, J. A. Comunidades tradicionais e neocomunidades. Rio de Janeiro: Contra Capa, 2011.

LOPES, J. R. Terceiro setor: a organização das políticas sociais e a nova esfera pública. São Paulo em Perspectiva, São Paulo, v. 18, n. 3, p. 57-66, jul./set. 2004.

. Exclusão social e controle social. Estratégias contemporâneas de redução da sujeiticidade. Psicologia \& Sociedade, v. 18, n. 2, 2006.

Ajustes globais, novos condicionamentos sociais e políticas públicas. Um estudo do contexto econômico regional do Vale do Rio dos Sinos, RS. Programa de Pós-graduação em Ciências Sociais - Unisinos. Projeto de Pesquisa. 2007.

OJEDA, E. N. S. Uma concepção latino-americana: a resiliência comunitária. In: MELILLO, A.; OJEDA, E. N. S. (Org.). Resiliência: descobrindo as próprias fortalezas. Tradução Valério Campos. Porto Alegre: Artmed, 2005. p. 47-57.

PIZZIO, A. Reconhecimento e resiliência no cotidiano de quebradeiras de cocobabaçu. Estudos de Sociologia [online], Pernambuco, v. 1, n. 20, [s/p], 2014. Disponível em:

<http://www.revista.ufpe.br/revsocio/index.php/revista/article/view/341>.

Acesso em: 13 fev. 2015.

SEN, A. Desenvolvimento como liberdade. 3. ed. Tradução Laura T. Motta. Revisão Ricardo D. Mendes. São Paulo: Companhia das Letras, 2000.

SCHMINK, M.; WOOD, C. H. Conflitos sociais e a formação da Amazônia. Tradução Noemi Miyasaka Porro e Raimundo Moura. Belém: Ed. UFPA, 2012. SILVA, L. T. O multiculturalismo e a política de reconhecimento de Charles Taylor. NEJ, v. 11, n. 2, p. 313-322, jul./dez. 2006. Disponível em:

$<$ http://www6.univali.br/seer/index.php/nej/article/view/440 >. Acesso em: 25 fev. 2015.

TAYLOR, C. Argumentos filosóficos. São Paulo: Loyola, 2000. 
UNDP- UNITED NATIONS DEVELOPMENT PROGRAMME. Human Development Report 2014 - Sustaining Human Progress: reducing vulnerabilities and building resilience. Washington DC, USA, 2014. Disponível em:

<http://www.pnud.org.br/HDR/Relatorios-Desenvolvimento-HumanoGlobais.aspx?indiceAccordion=2\&li=li RDHGlobais\#2014 >. Acesso em: 27 jul. 2014.

YÚDICE, G. A conveniência da cultura: usos da cultura na era global. Tradução Marie-Anne Kremer. 2. ed. Belo Horizonte: UFMG, 2013.

\section{Artigo:}

Recebido em 03 de Novembro de 2015

Aceito em 22 de Junho de 2016

R. Inter. Interdisc. INTERthesis, Florianópolis, v.13, n.3, p.01-22 Set.-Dez. 2016 